\title{
Ostwald Ripening of the Platinum Nanoparticles in the Framework of the Modified LSW Theory
}

\author{
R. D. Vengrenovich, B. V. Ivanskii, I. I. Panko, S. V. Yarema, \\ V. I. Kryvetskyi, and M. O. Stasyk \\ Yuriy Fedkovych National University of Chernivtsi, Ukraine \\ Correspondence should be addressed to R. D. Vengrenovich; vengrenovich@i.ua
}

Received 25 February 2014; Accepted 1 June 2014; Published 9 September 2014

Academic Editor: Shijun Liao

Copyright (c) 2014 R. D. Vengrenovich et al. This is an open access article distributed under the Creative Commons Attribution License, which permits unrestricted use, distribution, and reproduction in any medium, provided the original work is properly cited.

An analysis of the experimental data related to the mechanism of Pt particles sintering has been carried out using the modified LSW theory. The size distribution for the Pt nanoparticles at the stage of Ostwald ripening fits the generalized Lifshitz-Slyozov-Wagner model calculated with the assumption of two parallel mechanisms involved in the nanoparticles growth (dissolution): diffusion and Wagner's (controlled by the chemical reaction rate). Comparison between the experimental histograms and the curves calculated theoretically proves the governing role of the Wagner's mechanism (chemical reaction) in the Pt nanoparticles growth.

\section{Introduction}

Advances in technologies, especially in nanotechnologies, cause significant interest towards Ostwald ripening (OR). It is well known that the nanoscaled particles $(1-100 \mathrm{~nm})$ can reveal new properties different from characteristics of the bulky substances and the potential market of the nanoapplications in different branches of science and technology such as electronics, optoelectronics, information technology, medicine, and pharmacology is very wide [1]. On the other hand, OR can take place in some nanosystems because of the Gibbs-Thomson effect, and this phenomenon results in gradual growing of the bigger particles at the expense of smaller ones. Therefore, the smaller nanoclusters or nanocrystals (NC) dissolve while the bigger ones grow. This process also causes rise in the particles mean size, widening of the NC size distribution and dispersion. As a result, this process can worsen specific characteristics and performance of the nanosystem or even cause its complete degradation. Thus, OR is an unwanted effect and the investigation of its mechanism and kinetics of the NC growing/dissolution through OR can open new opportunities in controlling this process and minimization of its negative effects.
On the other hand, there are tight links between OR and the nanotechnologies. The process of a new phase formation always includes three stages regardless of the synthesis method used or the source phase (liquid, solid, or gaseous): nucleation, independent growing of the new nanoparticles, and their Ostwald ripening. The latter stage is governed by the Gibbs-Thomson effect and many useful characteristics of new nanoparticles are formed exactly during this stage [2].

The late OR takes place when oversaturation of the synthesis solution reduces to the level when new clusters do not appear any more. Then the process of the clusters size redistribution starts and the process of OR completes the final size range and dispersion [3].

A size distribution function reflecting the most complete information related to the structural composition of the nanosystem can be calculated for the given growing mechanism and nanoclusters shape using some available theoretical approaches [4-9].

The main requirements towards structural characteristics of the applicable NC can be outlined as follows. Regardless of the synthesis method used, NC should have uniform size, shape, composition, lattice structure, and other technical parameters. Besides, the size distribution should be as narrow as possible and the dispersion should be kept low. 
The two separate growing mechanisms were analyzed by the primary $L S W$ theory: the diffusion mechanism controlled by the bulk diffusion coefficient $D_{v}$ as introduced by Lifshitz and Slyozov $[4,5]$ and Wagner's mechanism controlled by the rate of the chemical bonds formation or the surface chemical reaction rate [6].

Both mechanisms are analyzed simultaneously in the framework of the modified $L S W$ theory. A ratio between two subfluxes of the matter towards/outwards the NC surface, diffusion $j_{v}$ and Wagner's $j_{i}$, represents a contribution of each mechanism into the resulting process of $\operatorname{OR}[9,10]$. These contributions depend on many parameters such as nature of NC, temperature, and synthesis method.

It should be mentioned that many important applications in electronics, optoelectronics, solar energy conversion, and other branches are reported [11-18] for the semiconducting nanoscaled heterosystems containing quantum dots [1923]. The OR stage is known for such systems that were usually synthesized using the molecular-beam epitaxy in the Stranski-Krastanov mode before [24]. More advanced and less expensive methods such as dripping, liquid phase, and electrophase epitaxy are also used for this synthesis now [2529].

As seen from [30-34], significant progress is achieved in the synthesis of the quantum dots semiconductors using various chemical and colloid methods. For instance, nanocrystals of $\mathrm{ZnO}$ (one of the most universal and multifunctional semiconductors) are synthesized usually from oversaturated solutions [35-45].

As reported in [46-49], the modified $L S W$ theory $[9,10]$ proves that the growing of NC in the nanosystems in many cases involves both mechanisms (diffusion and Wagner's) [46].

This paper is devoted to the investigation of the governing role of OR in the process of Pt NC sintering that occurs in a nanocomposite material and involves both mechanisms of growing. The carbon nanotubes are used in this synthesis as reported in [47].

Evaluation of the sintering process has been performed using temporal evolution of the particles size distribution during heating from the initial temperature to $550^{\circ} \mathrm{C}$ and then to $800^{\circ} \mathrm{C}$. The size distribution of $\mathrm{Pt} \mathrm{NC}$ changed from the Gauss type to the normal logarithmic type under such heating mode [47]. Since this sintering process runs according to OR mechanism, the particles size distribution function is expected to agree with the theoretical $L S W$ distribution.

As a result, the experimental histograms [47] should also be in agreement with the theoretical distributions calculated using the modified LSW theory and the generalized LifshitzSlyozov-Wagner distribution.

\section{The Fundamental of the Modified LSW Theory Applied to the Pt Nanoparticles Sintering in a Nanocomposite}

The initial average size of the Pt particles in the nanocomposite was 2,62 $( \pm 0,6) \mathrm{nm}$ [47]. A nanoparticle of such size is unstable thermodynamically since its specific surface is comparatively large, which results in high free energy value. As a system goes to the equilibrium, its free energy decreases and the particles average size grows.

It should always be taken into consideration that the nanoparticles are very small and approximate amounts of their surface and body atoms are similar, which causes higher reactivity of the particles. That is why the surface and the interface processes should be considered together with the regular diffusion transportation in order to analyze growth and dissolution of nanoparticles. In other words, Wagner's (kinetic) mechanism of the nanoparticle growth/dissolution cannot be neglected in this case of OR of the Pt NC and both processes, diffusion and chemical reaction, should be taken into account for OR in the disperse phase of the nanosystems.

Two mechanisms of the nanocrystal (NC) growth are analyzed by the modified LSW theory $[9,10]$. One of them is the diffusion mechanism (diffusion) introduced by Lifshitz and Slyozov $[4,5]$ while the second mechanism is Wagner's kinetic growth [6] controlled by the chemical reaction rate. According to this theory the flux of atoms towards/outwards NC $j$ can be represented as a sum of the diffusion $j_{v}$ and kinetic $j_{i}$ subfluxes:

$$
j=j_{v}+j_{i}
$$

This equation represents the basic idea of the modified LSW theory, which means two parallel mechanisms (diffusion and Wagner's) of the NC growth.

The rate of the NC growth $\dot{r} \equiv d r / d t$ should be defined to obtain a function $f(r, t)$ describing the temporal evolution of the size distribution for the NCs. It is known that the continuity equation can be used to couple $f(r, t)$ and $\dot{r}$

$$
\frac{\partial f(r, t)}{\partial t}+\frac{\partial}{\partial r}[f(r, t) \cdot \dot{r}]=0 .
$$

The rate of growth $\dot{r}$ can be defined using the condition

$$
\frac{d}{d t}\left(\frac{4}{3} \pi r^{3}\right)=j v_{m}
$$

where $j$ is determined by (1). After several simple transformations we can obtain from (3)

$$
\frac{d r}{d t}=\frac{B^{*}}{r}\left(\frac{x}{1-x} \frac{r_{g}}{r}+1\right)\left(\frac{r}{r_{g}} \frac{r_{g}}{r_{k}}-1\right),
$$

or

$$
\frac{d r}{d t}=\frac{A^{*}}{r^{2}}\left(\frac{1-x}{x} \frac{r}{r_{g}}+1\right)\left(\frac{r}{r_{g}} \frac{r_{g}}{r_{k}}-1\right),
$$

where $B^{*}=2 \sigma C_{\infty} v_{m}^{2} \beta / k T, A^{*}=3 \sigma C_{\infty} v_{m}^{2} D_{v} / k T, x=j_{v} / j$, $1-x=j_{i} / j, x /(1-x)=j_{v} / j_{i}, r$ is radius of the particle, $r_{g}$ is the maximal size of NC, $r_{k}$ is critical radius of $\mathrm{NC}$, which is equal to the average size $\langle r\rangle\left(r_{k} \equiv\langle r\rangle\right)$ as set by the LSW theory, and $\sigma$ is the specific surface energy; $C_{\infty}$ is the equilibrium concentration of the dissolved substance; $v_{m}$ is volume of atom of the dissolved substance; $\beta$ is the kinetic coefficient determining the $j_{i}$ subflux; $D_{v}$ is the coefficient of bulk diffusion; $k$ is Boltzmann's constant, and $T$ is temperature. 
Equation (4) describes the rate of the Pt NC growth governed mostly by the kinetic subflux $j_{i}$ with partial contribution $x$ made by the diffusion subflux $j_{v}$. On the contrary, (5) describes the rate of the Pt NC growth governed mostly by the diffusion subflux $j_{v}$ with partial contribution $(1-x)$ made by the kinetic subflux. Therefore, the rates of growth (4) and (5) can be represented in the $L S W$ theory by the ratio between subfluxes $j_{v}$ and $j_{i}$.

According to [48], $f(r, t)$ can be represented by the product of two functions: one depending on time $t$ and another depending on the relative variable $u$ :

$$
f(r, t)=\frac{1}{r_{g}^{4}} g(u),
$$

where $r_{g}$ depends on time and

$$
g(u)=Q \cdot g^{\prime}(u),
$$

$Q=3 M / 4 \pi \rho \int_{0}^{1} u^{3} g^{\prime}(u) d u, M$ is total mass of the NCs in the unit of volume, and $\rho$ is density of the NC's substance.

A definition of the relative variable in the form

$$
u=\frac{r}{r_{g}},
$$

instead of the traditional form $\rho=r / r_{k}$, was proposed in [48], and in this way the variation interval of $u$ became independent on the growth mechanism of the NC $(0 \leq$ $u \leq 1$ ). Function $g(u)$ in form (7) (or function $g^{\prime}(u)$ (with accuracy to the constant $Q$ )) represents the generalized distribution of Lifshitz-Slyozov-Wagner (GDLSW), which involves simultaneously two mechanisms of growth diffusion and Wagner's.

The distribution $g^{\prime}(u)$ can be obtained by integration of (2) with account of (4) or (5) and proceeding from differentiation by $r$ and $t$ to differentiation by $u[9,10]$

$$
g^{\prime}(u)=u^{2}(1-u)^{B}\left(u+x^{2}+x\right)^{D} \exp \left(\frac{C}{1-u}\right),
$$

where

$$
\begin{aligned}
& B=\frac{2 x^{4}+4 x^{3}+12 x^{2}+10 x+5}{F}, \\
& D=-\frac{4 x^{4}+8 x^{3}+6 x^{2}+2 x+1}{F}, \\
& C=-\frac{3 x^{2}+3 x+3}{F} \\
& F=x^{4}+2 x^{3}+3 x^{2}+2 x+1 .
\end{aligned}
$$

Assuming $x=0, B=5, D=-1$, and $C=-3$, (9) transforms (with accuracy to the constant $Q$ ) into Wagner's distribution [6]

$$
g^{\prime}(u)=u(1-u)^{-5} \exp \left(-\frac{3}{1-u}\right) .
$$

Assuming $x=1, B=11 / 3, D=-7 / 3$, and $C=-1$, (9) matches the Lifshitz-Slyozov distribution $[4,5]$

$$
g^{\prime}(u)=u^{2}(1-u)^{-11 / 3}(u+2)^{-7 / 3} \exp \left(-\frac{1}{1-u}\right) .
$$

The GDLSW distribution (7) can represent adequately the size distribution for $0 \leq x \leq 1$. As the average size $\langle r\rangle$ (or critical size $r_{k}$ ) is growing continuously during OR, the maximum size $r_{g}$ grows as well, although the ratio $r_{g} / r_{k}$ remains unchanged. According to the modified $L S W$ theory $[9,10]$

$$
\frac{r_{g}}{r_{k}}=\frac{2+x}{1+x}
$$

Considering Wagner's mechanism of the growing and assuming $x=0$, we obtain $r_{g} / r_{k}=2$ and for the diffusion mechanism and $x=1, r_{g} / r_{k}=3 / 2$.

Since the ratio $r_{g} / r_{k}$ is a time independent constant, the size distribution $g^{\prime}(u)$ does not depend on the initial distribution. Therefore, some generally used characteristics of $g^{\prime}(u)$ depending on the initial and central moments (dispersion $\left\langle u^{2}\right\rangle-\langle u\rangle^{2}$, the mean relative radius $\langle u\rangle$, area under the curve, etc.) also do not depend on time during OR.

The function $f(r, t)(6)$ describes the temporal evolution of the size distribution. The time dependence of $r_{g}$ should be determined in order to define the explicit mode of this function. The value $r_{g}$ can be found from (4) and (5) by substituting $r_{g}$ for $r$ and a value of the ratio $r_{g} / r_{k}$ taken from (13) for this ratio. Integrating (4) for the preliminary Wagner's mechanism we obtain

$$
\begin{gathered}
r_{g}^{2}=B^{*} \frac{1}{1-x^{2}} t, \\
r_{k}^{2}=B^{*} \frac{1+x}{(1-x)(2+x)^{2}} t .
\end{gathered}
$$

Assuming $x=0$, we obtain $r_{g}^{2}=B^{*} t, r_{k}^{2}=(1 / 4) B^{*} t$, and $r_{g} / r_{k}=2$.

Alternatively, integrating (5) for the preliminary diffusion (diffusion) mechanism we obtain

$$
\begin{aligned}
& r_{g}^{3}=A^{*} \frac{1}{x(1+x)} t, \\
& r_{k}^{3}=A^{*} \frac{(1+x)^{2}}{x(2+x)^{3}} t .
\end{aligned}
$$

Assuming $x=1$, we obtain $r_{g}^{3}=(1 / 2) A^{*} t, r_{k}^{3}=(4 /$ 27) $A^{*} t$, and $r_{g} / r_{k}=3 / 2$.

Finally, the function $f(r, t)(6)$ can be defined from the dependence of $r_{g}$ on $t$.

\section{Discussion}

The distribution (7) is shown in Figure 1(a) as a series of curves for various $x$ and Wagner's distribution $(x=0)$ is shown in the embedment. The $x=1$ curve corresponds to 


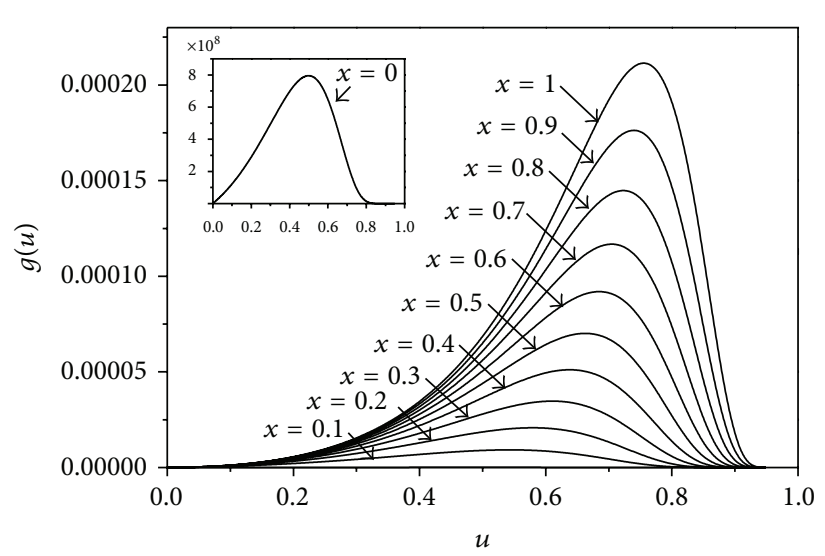

(a)

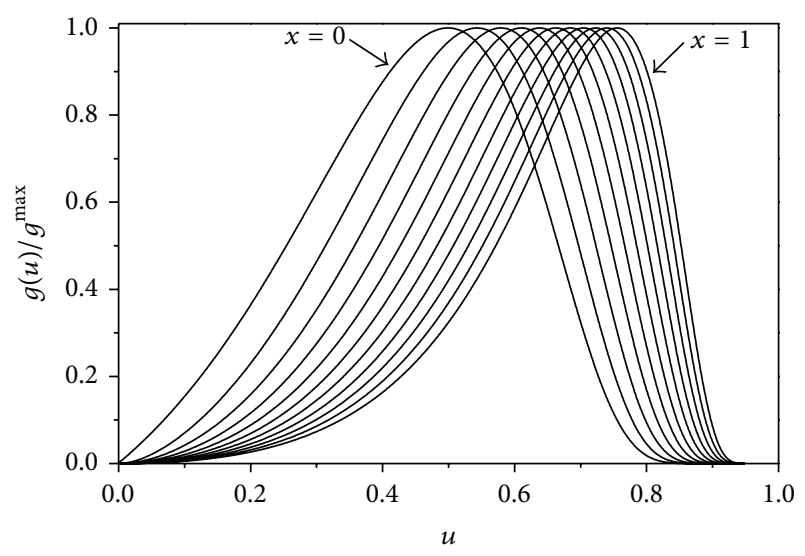

(b)

FIGURE 1: The curves corresponding to the GDLSW distribution calculated using the formula (7) with the iteration step $\Delta x=0.1$ (a); same curves as in (a) normalized by their maximums (b).

the Lifshitz-Slyozov distribution. The same curves normalized by their maximums are shown in Figure 1(b). Such curves can be easily compared to the experimental data.

The experimental histogram should be presented in the same normalized mode as the theoretical curves in order to perform their comparison. The scale of the horizontal axis (it represents radii $r$ or diameters $d$ of NC in nm) should be transferred to the relative variable (relative diameter) $u=$ $r / r_{g}=d / d_{g}$, where the maximal diameter $d_{g}$ is taken from the histogram. The relative diameter of $\mathrm{NC} u$ in the histogram will be ranged between 0 and 1 after such transformation.

All values in the vertical axis corresponding to the number of particles in the unit of volume within some interval $\Delta d$ are normalized by the maximum of histogram. Therefore, the histogram is normalized by the unit along all axes. The conformity or inconformity in the theoretical and experimental data can be evaluated through comparison of the experimental histograms and the normalized theoretical curves built in the same scale. The initial and central moments calculated for the experimental and theoretical distributions should be compared in order to perform the quantitative comparison.

The comparison between the normalized experimental histograms of the Pt NC [47] and the theoretical curves is shown in Figure 2. The histogram (a) shows the initial size distribution of the Pt particles and it can be noticed that this histogram and the GDLSW distribution (7) at $x=0,2$ are in good agreement.

This fact confirms that the OR stage is present even in the liquid phase synthesis of the Pt NC and that the chemical reaction running on the $\mathrm{Pt} \mathrm{NC}$ surface is the governing factor of OR.

It should be emphasized that the OR stage has been identified and reported using the colloid chemistry methods in some liquid phase syntheses of NC (including semiconducting NC) [32, 49-51].

Having calculated the ratio $r_{g} / r_{k}(13)$ and the mean radius of the Pt particles $(\langle r\rangle=2,62( \pm 0,6) \mathrm{nm}$ ) (in the framework of the $L S W$ theory this radius corresponds to the critical value $r_{k}$ ), the maximal radius $r_{g}$ of the Pt NC can be calculated as

$$
r_{g}=r_{k} \frac{2+x}{1+x}
$$

where $x=0,2$ as follows from Figure 2(a). Within the measurement error, the maximal size calculated by (16) $r_{g}=$ $4,8 \mathrm{~nm}$ is in good agreement with the maximal size of $\mathrm{Pt} \stackrel{\mathrm{NC}}{\mathrm{N}}$ $r_{g} \approx 4,3 \mathrm{~nm}$ measured experimentally.

A mean size of $\mathrm{NC}$ rises up to $(\langle r\rangle=8,58( \pm 2,45) \mathrm{nm})$ [47] and their sphericity becomes more perfect as a result of thermotreatment of nanocomposites at $550^{\circ} \mathrm{C}$. The histogram (b) in Figure 2 shows size distribution for the particles at $550^{\circ} \mathrm{C}$, and it is easily noticeable that it fits with the GDLSW distribution at $x=0,1$, which is very close to Wagner's distribution. The maximal size $r_{g}$ according to the histogram (b) is $16,5 \mathrm{~nm}$, and according to the formula (16) it is about $16,4 \mathrm{~nm}$. This agreement seems too good and can be a result of significant errors committed in the plotting of the experimental histograms. However, two conclusions can be drawn from the results seen in Figure 2(a): first, as noticed in [47], the shapes of the histograms (a) and (b) are quite close; second, the rate of the Pt NC growth/dissolution during their sintering is controlled by the surface chemical reaction running on the NC, that is, Wagner's mechanism. Faster diffusion processes (diffusion) do not control OR.

Further rise in the NC sizes occurs at rise in temperature of the nanocomposites thermotreatment and an average size of the $\mathrm{Pt} \mathrm{NC}$ reaches $(\langle r\rangle=15,89( \pm 5,23) \mathrm{nm})$ at $800^{\circ} \mathrm{C}[47]$. A histogram reflecting sizes distribution for the $800^{\circ} \mathrm{C}$ sintering of Pt NC is shown in Figure 2(c). Similar to the previous cases (a) and (b), Wagner's distribution or the GDLSW model at $x=0,1$ is in good agreement with the (c) histogram. This is another proof of the governing role of the kinetically controlled Wagner's mechanism of the Pt NC sintering at $800^{\circ} \mathrm{C}$. This process is one of infrequent examples of the disperse particles growth/dissolution involving OR totally controlled by the surface chemical reaction. 


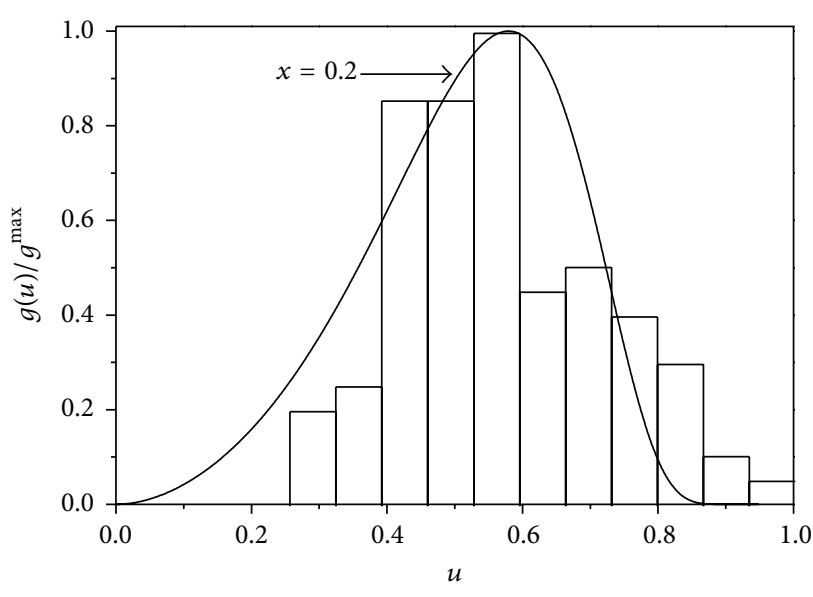

(a)

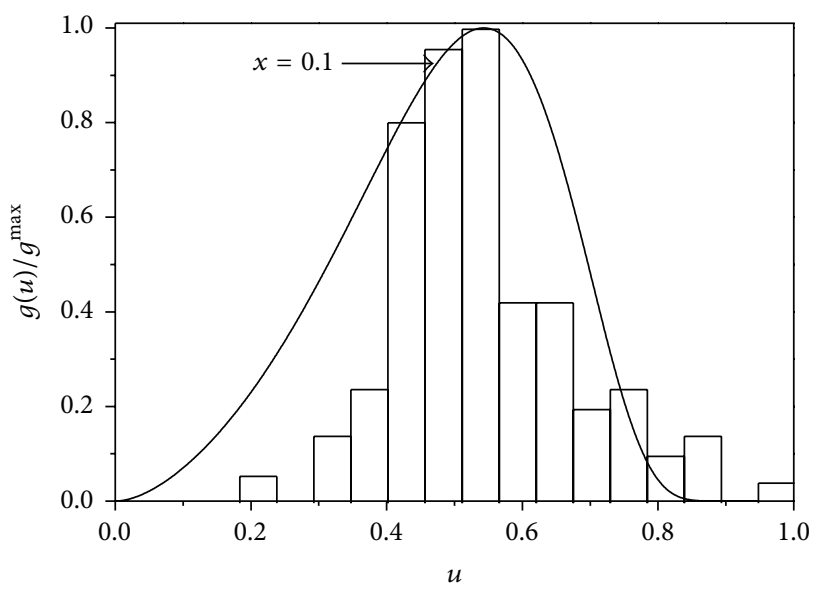

(b)

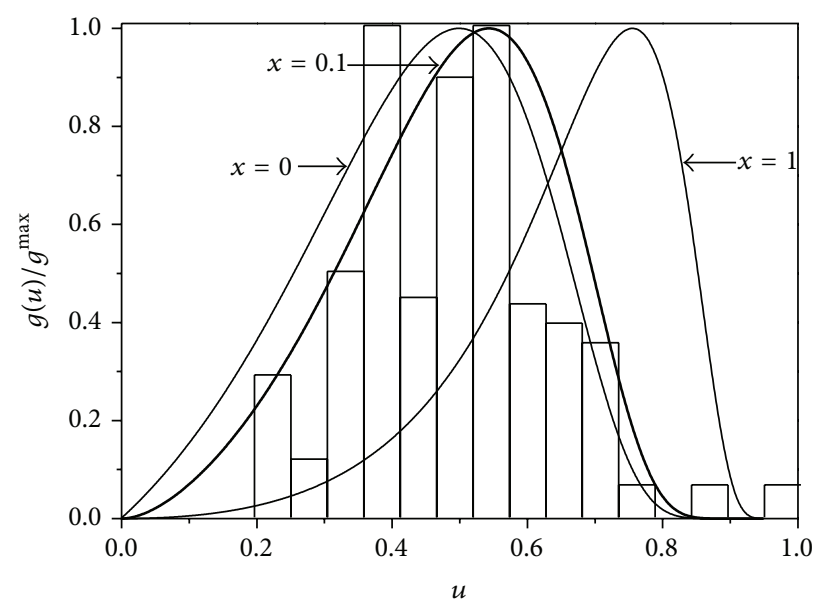

(c)

FIgURE 2: Comparison of the experimental Pt NC histograms with the theoretical GDLSW distributions: (a) source histogram; (b) heating to $550^{\circ} \mathrm{C}$; and (c) heating to $800^{\circ} \mathrm{C}$.

Good agreement between the maximal sizes of Pt NC $r_{g}$ derived from the experimental histograms and calculated using the formula (16) also confirms correctness of comparison between the experimental and the theoretical size distributions. For example the maximal size calculated using (16) for $800^{\circ} \mathrm{C}$ is $r_{g}=31,8 \mathrm{~nm}$, while the experimental value is $r_{g}=33,9 \mathrm{~nm}$. Taking into account the experimental error, this difference is rather insufficient.

Therefore, the modified LSW theory is an adequate tool for the description of the Pt NC sintering according to the OR mechanism within the entire temperature range considered in this paper.

\section{Conclusion}

A theoretical analysis of the Pt NC sintering has been performed within some temperature range using the modified $L S W$ theory. The theoretical GDLSW distribution with the $x$ value about the unit can adequately describe the experimental size distribution for the Pt NC. Therefore, only the surface chemical reaction on the Pt NC (Wagner's mechanism) governs the processes of growing/dissolution of the nanoparticles at the stage of OR. Moreover, the same mechanism also controls the process of the $\mathrm{Pt} \mathrm{NC}$ growth/dissolution during their liquid phase synthesis. This is one of infrequent examples of OR for nanoparticles that is totally controlled by the chemical reaction according to Wagner's mechanism. This conclusion can be proven by comparison of the source experimental histograms and theoretical curves built according to the GDLSW approximation at $x=0,2$.

Analysis of the high temperature sintering of Pt NC shows good agreement between the experimental and theoretical maximum sizes of the particles $r_{g}$ and brings another evidence for correctness of the above theory.

\section{Conflict of Interests}

The authors declare that there is no conflict of interests regarding the publication of this paper. 


\section{References}

[1] U. Hartmann, Faszination Nanotechnologie, vol. 8, Elsevier, Spektrum Akademischer, Munich, Germany, 2006.

[2] W. Ostwald, "Über die vermeintliche isometric des roten undgelben quecksilberxyds und die oberflachenspannung fester körper," Zeitschrift für Physikalische Chemie, vol. 34, pp. 495503, 1900.

[3] R. D. Vengrenovich, Y. V. Gudyma, and S. V. Yarema, "Ostwald ripening of nanostructures with quantum dots," Fizika $i$ Tekhnika Poluprovodnikov, vol. 35, no. 12, pp. 1440-1444, 2001.

[4] I. M. Lifshits and V. V. Slyozov, "On kinetics of diffusion decay of oversaturated solid solutions," Journal of Experimental and Theoretical Physics, vol. 35, pp. 479-492, 1958.

[5] I. M. Lifshitz and V. V. Slyozov, "The kinetics of precipitation from supersaturated solid solutions," Journal of Physics and Chemistry of Solids, vol. 19, no. 1-2, pp. 35-50, 1961.

[6] C. Wagner, "Theorie der alterung von niderschlagen durch umlösen (Ostwald Reifung)," Zeitschrift für Elektrochemie, vol. 65, pp. 581-591, 1961.

[7] V. V. Slyozov, "Coalescence of the supersaturated solid solution in the case of diffusion block boundaries or dislocation lines," Fizika Tverdogo Tela, vol. 9, no. 4, pp. 1187-1191, 1967.

[8] V. V. Slyozov and V. V. Sagalovich, "Diffusive decomposition of solid solutions," Uspekhi Fizicheskikh Nauk, vol. 151, no. 1, pp. 67-104, 1987.

[9] R. D. Vengrenovich, B. V. Ivanskii, and A. V. Moskalyuk, "Generalized Lifshitz-Slyozov-Wagner distribution," Journal of Experimental and Theoretical Physics, vol. 131, pp. 1040-1047, 2007.

[10] R. D. Vengrenovich, B. V. Ivanskyi, and A. V. Moskalyuk, "Generalized chakraverty-wagner distribution," Ukrainian Journal of Physics, vol. 53, no. 11, pp. 1101-1109, 2008.

[11] M. H. Huang, S. Mao, H. Feick et al., "Room-temperature ultraviolet nanowire nanolasers," Science, vol. 292, no. 5523, pp. 1897-1899, 2001.

[12] X. W. Sun, J. Z. Huang, J. X. Wang, and Z. Xu, "A ZnO nanorod inorganic/organic heterostructure light-emitting diode emitting at 342 nm," Nano Letters, vol. 8, no. 4, pp. 1219-1223, 2008.

[13] Y. Jin, J. Wang, B. Sun, J. C. Blakesley, and N. C. Greenham, "Solution-processed ultraviolet photodetectors based on colloidal ZnO nanoparticles," Nano Letters, vol. 8, no. 6, pp. 16491653, 2008.

[14] C. Lizandara-Pueyo, S. Siroky, M. R. Wagner et al., "Shape anisotropy influencing functional properties: trigonal prismatic $\mathrm{ZnO}$ nanoparticles as an example," Advanced Functional Materials, vol. 21, no. 2, pp. 295-304, 2011.

[15] L. Spanhel, "Colloidal $\mathrm{ZnO}$ nanostructures and functional coatings: a survey," Journal of Sol-Gel Science and Technology, vol. 39, no. 1, pp. 7-24, 2006.

[16] A. B. Djurišić and Y. H. Leung, "Optical properties of $\mathrm{ZnO}$ nanostructures," Small, vol. 2, pp. 944-961, 2006.

[17] K. L. Chopra and S. R. Das, Eds., Thin Film Solar Cells, Plenum, New York, NY, USA, 1983.

[18] S. Hingorani, V. Pillai, P. Kumar, M. S. Multani, and D. O. Shah, "Microemulsion mediated synthesis of zinc-oxide nanoparticles for varistor studies," Materials Research Bulletin, vol. 28, no. 12, pp. 1303-1310, 1993.

[19] O. P. Pchelyakov, Y. B. Nikiforov, A. I. Yakimov, and B. Foyhtlender, "Silicon-germanium nanostructures with quantum dots: formation mechanisms and an electric properties," Fizika i Tekhnika Poluprovodnikov, vol. 34, pp. 1281-1299, 2000.
[20] O. P. Pchelyakov, Y. B. Nikiforov, A. I. Yakimov, and B. Foyhtlender, "Nucleation of coherent semiconductor islands during stranski-krastanow growth induced by elastic stresses," Fizika i Tekhnika Poluprovodnikov, vol. 36, pp. 1177-1185, 2002.

[21] V. N. Nevedomskyi, N. A. Bert, V. V. Chaldyshev, V. V. Preobrazhenskyi, M. A. Putiato, and B. R. Semiahin, "GaAs structures with InAs and As quantum dots produced in a single process of molecular beam epitaxy," Fizika i Tekhnika Poluprovodnikov, vol. 43, pp. 1662-1666, 2009.

[22] M. Bürger, T. Schupp, K. Lischka, and D. J. As, "Cathodoluminescence spectroscopy of zinc-blende GaN quantum dots," Physica Status Solidi (C): Current Topics in Solid State Physics, vol. 9, no. 5, pp. 1273-1277, 2012.

[23] P.-S. Kuo, B.-C. Hsu, P.-W. Chen, P. S. Chen, and C. W. Liu, "Recessed oxynitride dots on self-assembled Ge quantum dots grown by LPD," Electrochemical and Solid-State Letters, vol. 7, no. 10, pp. G201-G203, 2004.

[24] I. N. Stranski and L. Krastanov, "Abhandlungen der mathematisch-naturwissenschaftlichen klasse IIb," Akademie der Wissenschaften Wien, vol. 146, pp. 797-810, 1938.

[25] Z. R. Tian, J. A. Voigt, J. Liu et al., "Complex and oriented ZnO nanostructures," Nature Materials, vol. 2, no. 12, pp. 821-826, 2003.

[26] C. Pacholski, A. Kornowski, and H. Weller, "Self-assembly of $\mathrm{ZnO}$ : from nanodots to nanorods," Angewandte ChemieInternational Edition, vol. 41, pp. 1188-1191, 2002.

[27] C. Ribeiro, E. J. H. Lee, E. Longo, and E. R. Leite, "A kinetic model to describe nanocrystal growth by the oriented attachment mechanism," ChemPhysChem, vol. 6, no. 4, pp. 690-696, 2005.

[28] R. Bandyopadhyaya, R. Kumar, K. S. Gandhi, and D. Ramkrishna, "Modeling of precipitation in reverse micellar systems," Langmuir, vol. 13, no. 14, pp. 3610-3620, 1997.

[29] M. Ethayaraja, K. Dutta, and R. Bandyopadhyaya, "Mechanism of nanoparticle formation in self-assembled colloidal templates: population balance model and Monte Carlo simulation," Journal of Physical Chemistry B, vol. 110, no. 33, pp. 16471-16481, 2006.

[30] M. Ethayaraja and R. Bandyopadhyaya, "Population balance models and Monte Carlo simulation for nanoparticle formation in water-in-oil microemulsions: Implications for CdS synthesis," Journal of the American Chemical Society, vol. 128, no. 51, pp. 17102-17113, 2006.

[31] R. Bandyopadhyaya, R. Kumar, and K. S. Gandhi, "Modelling of $\mathrm{CaCO}_{3}$ nanoparticle formation during overbasing of lubricating oil additives," Langmuir, vol. 17, no. 4, pp. 1015-1029, 2001.

[32] A. Layek, G. Mishra, A. Sharma et al., "A generalized three-stage mechanism of $\mathrm{ZnO}$ nanoparticle formation in homogeneous liquid medium," Journal of Physical Chemistry C, vol. 116, no. 46, pp. 24757-24769, 2012.

[33] A. de Kergommeaux, J. Faure-Vincent, A. Pron, R. de Bettignies, B. Malaman, and P. Reiss, "Surface oxidation of tin chalcogenide nanocrystals revealed by 119 Sn-Mössbauer spectroscopy," Journal of the American Chemical Society, vol. 134, no. 28, pp. 1165911666, 2012.

[34] S. Sapra and D. D. Sarma, "Growth kinetics of ZnO nanocrystals: a few surprises," Physical Review B-Condensed Matter and Materials Physics, vol. 69, Article ID 125304, 2004.

[35] R. Viswanatha, S. Sapra, T. Saha-Dasgupta, and D. D. Sarma, "Electronic structure of and quantum size effect in III-V and IIVI semiconducting nanocrystals using a realistic tight binding 
approach," Physical Review B-Condensed Matter and Materials Physics, vol. 72, no. 4, Article ID 045333, 2005.

[36] G. Oskam, Z. Hu, R. L. Penn, N. Pesika, and P. C. Searson, "Coarsening of metal oxide nanoparticles," Physical Review EStatistical, Nonlinear, and Soft Matter Physics, vol. 66, no. 1, Article ID 011403, 4 pages, 2002.

[37] P. E. Lippens and M. Lannoo, "Calculation of the band gap for small CdS and ZnS crystallites," Physical Review B-Condensed Matter and Materials Physics, vol. 39, no. 15, pp. 10935-10942, 1989.

[38] S. Sapra, N. Shanthi, and D. D. Sarma, "Realistic tight-binding model for the electronic structure of II-VI semiconductors," Physical Review B-Condensed Matter and Materials Physics, vol. 66, no. 20, Article ID 205202, 8 pages, 2002.

[39] R. Viswanatha, H. Amenitsch, and D. D. Sarma, "Growth kinetics of $\mathrm{ZnO}$ nanocrystals: a few surprises," Journal of the American Chemical Society, vol. 129, no. 14, pp. 4470-4475, 2007.

[40] S. Iijima, "Helical microtubules of graphitic carbon," Nature, vol. 354, no. 6348, pp. 56-58, 1991.

[41] A. V. Eletskii, "Carbon nanotubes and their emission properties," Uspekhi Fizicheskih Nauk, vol. 172, pp. 401-438, 2002.

[42] P. N. Diachkov, "Carbon nanotubes: materials for computers XXI century," Priroda, vol. 11, pp. 23-30, 2000.

[43] S. J. Tans, M. H. Devoret, H. Dai et al., "Individual single-wall carbon nanotubes as quantum wires," Nature, vol. 386, no. 6624, pp. 474-477, 1997.

[44] W. Choi, "Carbon nanotubes for full color field-emission displays," Japanese Journal of Applied Physics, vol. 39, no. 1, pp. 2560-2564, 2000.

[45] J.-M. Bonard, T. Stöckli, O. Noury, and A. Châtelain, "Field emission from cylindrical carbon nanotube cathodes: possibilities for luminescent tubes," Applied Physics Letters, vol. 78, no. 18, pp. 2775-2777, 2001.

[46] R. Vengrenovich, B. Ivanskii, I. Panko, and M. Stasyk, "Size distribution of nanoparticles of $\mathrm{ZnO}$ and $\mathrm{SnS}$ in the frame of Lifshits-Slezov-Wagner modified theory," Journal of Physical Chemistry C, vol. 117, no. 26, pp. 13681-13687, 2013.

[47] C. Mateo-Mateo, C. Vázquez-Vázquez, M. Pérez-Lorenzo, V. Salgueiriño, and M. A. Correa-Duarte, "Ostwald ripening of platinum nanoparticles confined in a carbon nanotube/silicatemplated cylindrical space," Journal of Nanomaterials, vol. 2012, Article ID 404159, 6 pages, 2012.

[48] R. D. Vengrenovich, "On the Ostwald ripening theory. Overview 20," Acta Metallurgica, vol. 20, pp. 1079-1086, 1982.

[49] C. Lizandara-Pueyo, M. W. E. van den Berg, A. De Toni, T. Goes, and S. Polarz, "Nucleation and growth of $\mathrm{ZnO}$ in organic solvents-an in situ study," Journal of the American Chemical Society, vol. 130, no. 49, pp. 16601-16610, 2008.

[50] D. Segets, L. M. Tomalino, J. Gradl, and W. Peukert, "Real-time monitoring of the nucleation and growth of zno nanoparticles using an optical hyper-rayleigh scattering method," Journal of Physical Chemistry C, vol. 113, no. 28, pp. 11995-12001, 2009.

[51] A. P. Thurber, G. Alanko, G. L. Beausoleil II, K. N. Dodge, C. B. Hanna, and A. Punnoose, "Unusual crystallite growth and modification of ferromagnetism due to aging in pure and doped ZnO nanoparticles," Journal of Applied Physics, vol. 111, no. 7, Article ID 07C319, 2012. 

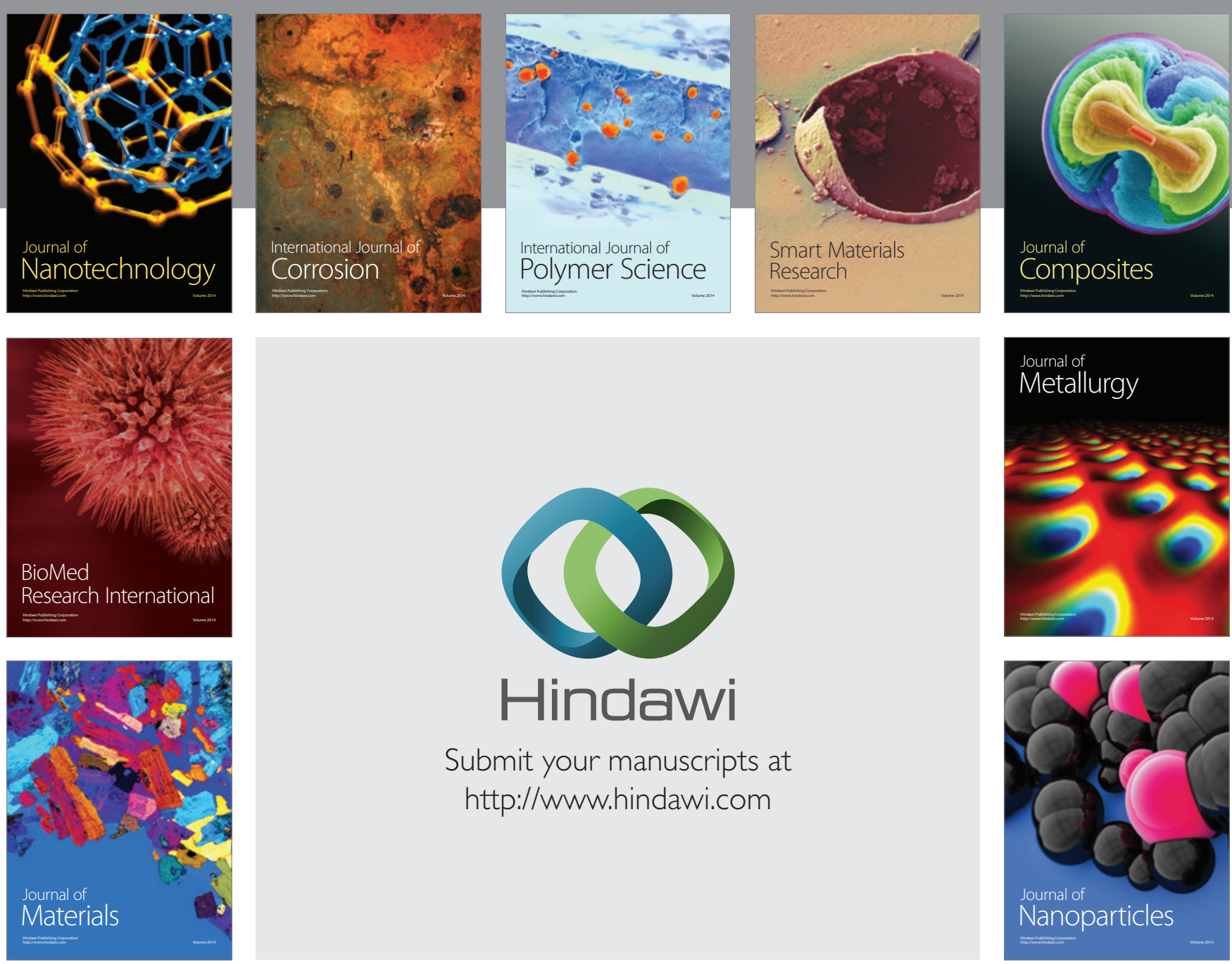

Submit your manuscripts at http://www.hindawi.com
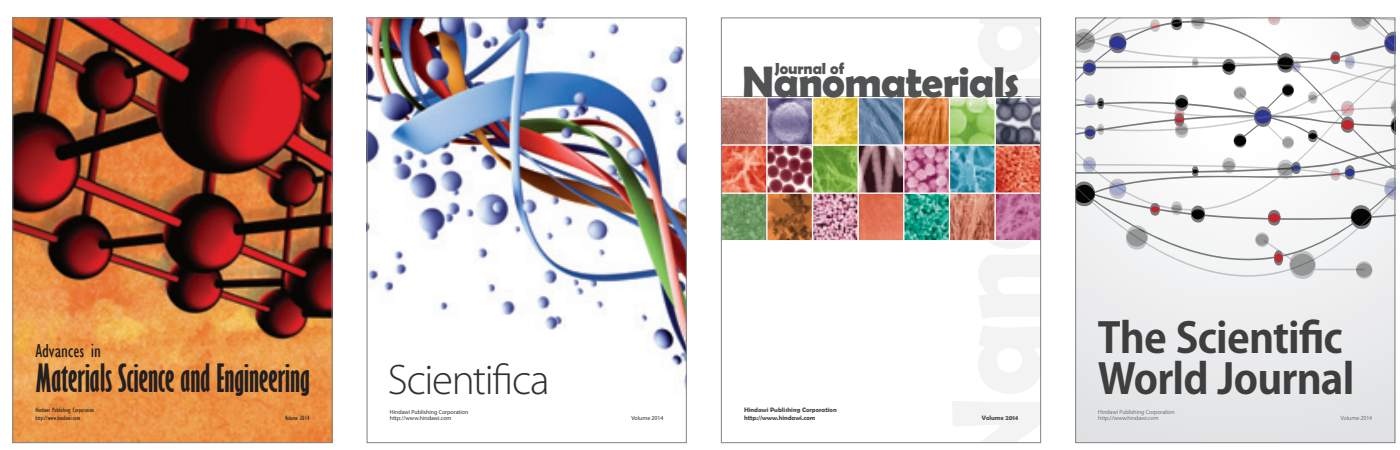

\section{The Scientific World Journal}
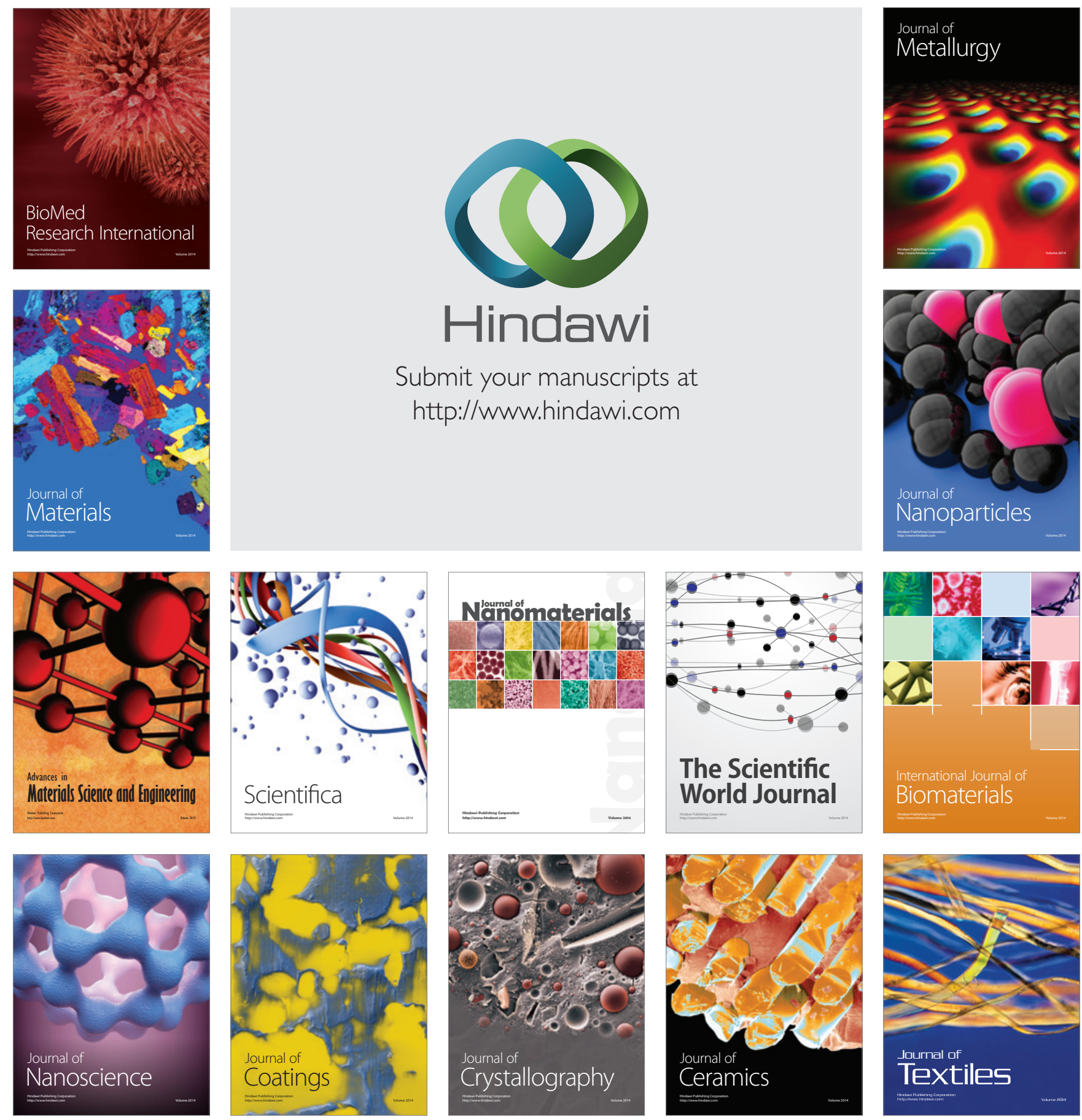